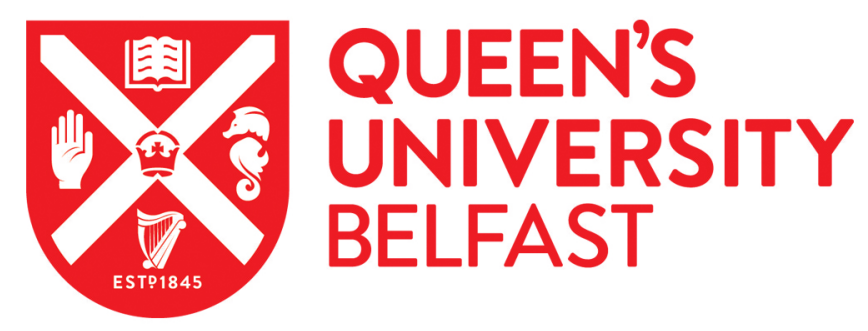

\title{
An Assessment of Sub-Meter Scale Spatial Variability of Arcellinida (Testate Lobose Amoebae) Assemblages in a Temperate Lake: Implications for Limnological Studies
}

Steele, R. E., Nasser, N. A., Patterson, R. T., Gregory, B. R. B., Roe, H. M., \& Reinhardt, E. G. (2018). An Assessment of Sub-Meter Scale Spatial Variability of Arcellinida (Testate Lobose Amoebae) Assemblages in a Temperate Lake: Implications for Limnological Studies. Microbial Ecology. https://doi.org/10.1007/s00248-0181157-5

Published in:

Microbial Ecology

\section{Document Version:}

Peer reviewed version

Queen's University Belfast - Research Portal:

Link to publication record in Queen's University Belfast Research Portal

\section{Publisher rights}

(C) 2018 Springer Science+Business Media.

This work is made available online in accordance with the publisher's policies. Please refer to any applicable terms of use of the publisher.

\section{General rights}

Copyright for the publications made accessible via the Queen's University Belfast Research Portal is retained by the author(s) and / or other copyright owners and it is a condition of accessing these publications that users recognise and abide by the legal requirements associated with these rights.

Take down policy

The Research Portal is Queen's institutional repository that provides access to Queen's research output. Every effort has been made to ensure that content in the Research Portal does not infringe any person's rights, or applicable UK laws. If you discover content in the

Research Portal that you believe breaches copyright or violates any law, please contact openaccess@qub.ac.uk. 
An Assessment of Sub-Meter Scale Spatial Variability of Arcellinida (Testate Lobose Amoebae) Assemblages in a Temperate Lake: Implications for Limnological Studies

Riley E. Steele ${ }^{\text {a }}$, Nawaf A. Nasser ${ }^{\text {a, }}{ }^{\text {, R. Timothy Patterson }}{ }^{\text {a }}$, Braden R.B. Gregory ${ }^{\text {a }}$, Helen M. Roe $^{\mathrm{b}}$, Eduard G. Reinhardt ${ }^{\mathrm{c}}$

(a) Ottawa-Carleton Geoscience Centre and Department of Earth Sciences and, Carleton University, 1125 Colonel By Drive, Ottawa, Ontario, K1S 5B6 Canada

(b) School of Natural and Built Environment, Queen's University, Belfast, United Kingdom BT7 $1 \mathrm{NN}$

(c) School of Geography and Earth Sciences, McMaster University, Hamilton, Ontario L8S 4K1 Canada

${ }^{1}$ Corresponding Author: Nawaf A. Nasser

E-mail: Nawafnasser@cmail.carleton.ca 


\section{Abstract}

Arcellinida (testate lobose amoebae), a group of benthic protists, were examined from 46 sediment-water interface samples collected from oligotrophic Oromocto Lake, New Brunswick, Canada. To assess (1) assemblage homogeneity at a sub-meter spatial scale, and (2) the necessity for collecting samples from multiple stations during intra-lake surveys, multiple samples were collected from three stations (quadrats 1,2 and 3) across the north basin of Oromocto Lake, with quadrat $1(n=16)$ being the furthest to the west, quadrat $2(n=15)$ situated closer to the center of the basin and quadrat $3(\mathrm{n}=15)$ positioned $300 \mathrm{~m}$ south of the mouth of Dead Brook, an inlet stream. Results from cluster analysis and Non-metric Multidimensional Scaling (NMDS) analysis identified two major Arcellinida assemblages, A1 and A2, the latter containing two subassemblages (A2a and A2b). Redundancy Analysis and Variance Partitioning results indicated that seven statistically significant environmental variables (K, S, Sb, Ti, Zn, Fe, and Mn) explained $41.5 \%$ of the total variation in the Arcellinida distribution. Iron, Ti and $\mathrm{K}$, indicators of detrital runoff, had the greatest influence on assemblage variance. The results of this study reveal that closely spaced samples $(\sim 10 \mathrm{~cm})$ in an open-water setting are comprised of homogenous arcellinidan assemblages, indicating that replicate sampling is not required. The results, however, must be tempered with respect to the various water properties and physical characteristics that comprise individual lakes as collection of several samples may likely be necessary when sampling multiple sites of a lake basin characterized by varying water depths (e.g. littoral zone vs. open water), or lakes impacted by geogenic or anthropogenic stressors (e.g. eutrophication, or industrial contamination).

Key words: Arcellinina, Lake sediments, New Brunswick, Intra-lake survey, Sub-meter scale sampling, Multivariate analysis. 


\section{Acknowledgements}

Funding for this research project was provided by NSERC Discovery and Carleton University Development grants awarded to RTP. Additional direct and in-kind funding was provided. We also thank Roy and Malcolm Patterson for their fieldwork assistance. Appreciation is also

extended to J.J. Wang, Nano Imaging Facility in Carleton University for assistance in obtaining SEM images. 


\section{Introduction}

Arcellinida (also known as testate lobose amoebae) are a group of unicellular benthic protozoans that is abundantly preserved in lake sediments from the equator to poles (e.g. [1-12]). While the group is most commonly described in Holocene lacustrine sediment records [13], its fossil record extends through the Phanerozoic and into the Neoproterozoic [14-16]. Arcellinida are mainly found in freshwater habitats (e.g. lakes, rivers and ponds; [1-13]) and, to a lesser extent, in brackish water settings, including tidal marshes $[17,18]$. The beret- or sac-like shaped tests (shells) of Arcellinida are either autogenous (secreted by the organism) or xenogenous (comprised of agglutinated grains obtained from the substrate), and range from ca. $30-300 \mu \mathrm{m}$ in size [19]. Through the last few decades, Arcellinida have become important environmental indicators in lacustrine studies due to their abundance in organic-rich sediments, rapid reproduction time (days to weeks), resistivity of their tests to decay and their sensitivity to a wide range of environmental variables (e.g. $\mathrm{pH}$, water temperature, salinity, eutrophication, and pollutants; [19]).

Arcellinida analyses are used to characterize ecosystem variability either within a lake (intra-lake) (e.g. [1-5, 7-11, 13-15, 20]) or between several lakes (inter-lake) (e.g. [4, 6, 7, 10, 11]). Intra-lake studies are useful for characterizing spatial patterns on a small-scale, while interlake studies are typically designed to provide information on a landscape scale. To enhance the quality of such spatial surveys, researchers strive to incorporate three critical components in their research design: (1) high quality and high-resolution sample recovery and data acquisition; (2) rapid collection and analysis of spatial data; and (3) cost-effectiveness. In reality, only one or two of these components is achieved as sampling a large number of lakes is generally laborious and is controlled by several constraints (e.g. limited time, resources, and/or budget). This is 
particularly true in many inter-lake studies where only one or two samples are collected from each lake under the assumption that one sample is an adequate representation of the lake environmental conditions $[4,12,20,21]$.

While intra-lake surveys are controlled by the same aforementioned constraints, researchers are often able to collect samples from multiple stations as moving from site to site within a lake is logistically easier than moving equipment between lakes. Such stations are usually distributed to maximize the spatial coverage and thus enhance the potential of capturing spatial environmental gradients across the sampled lake. In both inter- and intra-lake surveys, the collection of replicate samples from each station is often neglected as it is assumed that one sample is adequate to capture an Arcellinida assemblage composition representative of each station. However, when the aim of the study is to assess environmental gradients or the lake health using benthic bio-indicators, a patchy distribution of taxa could negatively influence assemblage characterization if an inadequate number of samples have been collected [22]. For example, studies carried out on marine benthic foraminifera, an allied group to Arcellinida, have demonstrated that the group often displays a patchy ecological distribution on relatively homogenous substrates, even at the sub-meter scale, which means that replicate sampling is often required to capture assemblage variability [22]. To test the validity of collecting a single sample from each station in intra-lake studies, Arcellinida assemblage homogeneity must be assessed at sub-meter scale in order to confirm, or refute, whether replicate samples are required to capture a representative assemblage composition. Although intra-lake surveys could easily be designed to test this assumption, this line of research has to date not been explored by arcellinidan researchers. Additionally, only a small number of Arcellinida-based intra-lake surveys currently exist, none of which were conducted at a sub-meter scale (e.g. [2, 3, 7]). 
The research presented in this paper is designed to assess whether Arcellinida show patchy distribution at sub-meter resolution and whether replicate sample collection at individual sample stations in a lacustrine open-water setting is required. The results of this research have implications for the development of future inter- and intra-lake sampling protocols involving assessment of arcellinidan faunas.

\section{Study Area}

Oromocto Lake is an oligotrophic lake located in SW New Brunswick, in the Tweedside district of the rural community of Harvey and is situated within the Saint John River Valley/ Highland Foothills [23]. The north basin of Oromocto Lake is characterized by a silty-mud substrate with varying aquatic vegetation cover and a small stream, Dead Brook, inflowing from the NE. The substrate variability observed in the north basin of Oromocto lake made it a suitable environment to: 1) test homogeneity (sample reproducibility) of arcellinidan assemblages obtained from closely spaced samples within relatively small one $\mathrm{m}^{2}$ quadrats; and 2) determine whether single or multiple samples are required from each station to generally characterize the Arcellinida faunas found in open water lake habitats with modest variation in submerged vegetation cover and additional influences, such as an inlet stream. 


\section{Materials and Methods}

\section{Study Design and Field Methods}

Forty-six sediment-water-interface samples were collected using a purpose built $1-\mathrm{m}^{2}$ quadrat (5x5 grid) from three stations in the north basin of Oromocto Lake in August 2016 (Figure 1, Figure 2). Each quadrat was partitioned into 25 square grids in order to facilitate high-resolution $10 \mathrm{~cm}$ replicate sample spacing. The siting of each quadrat within the basin was carefully determined in order to capture the full range of environmental heterogeneity in the open-water area of the basin. A YSI Professional Plus multiparameter instrument was used, at each site, to record changes in several water property parameters (e.g. pH, water temperature $\left[{ }^{\circ} \mathrm{C}\right]$, conductivity $[\mu \mathrm{s}]$, and dissolved oxygen [DO mgL-1]), all of which were found to be consistent across the basin. Therefore, the primary variables used in site selection were submerged aquatic vegetation cover and water depth. Sample stations were accessed by boat, with quadrat partitions being subsampled using SCUBA (RT Patterson was the diver), the only practical option for accurate, high-resolution sampling at $<1 \mathrm{~m}^{2}$ scale (Figure 2). The location of each sample station was logged using a Garmin 76CSx GPS, and substrate characteristics and water depth were assessed using LowranceHDS-7 side-scan sonar. Quadrat 1 (Q1; 45.641127º,$\left.-66.999987^{\circ} \mathrm{W}\right)$, characterized by the shallowest water depth $(3 \mathrm{~m})$ of the three quadrants, was located furthest west in an area where there was nearly complete coverage $(\sim 92 \%)$ of the substrate by vegetation. Quadrat $2\left(\mathrm{Q} 2 ; 45.641914^{\circ} \mathrm{N},-66.997589^{\circ} \mathrm{W}\right)$ was positioned in the middle of the basin in deeper water (5 m) with slightly less vegetation cover ( 66\%). Quadrat $3\left(\mathrm{Q} 3 ; 45.642866^{\circ} \mathrm{N}\right.$, $\left.66.994968^{\circ} \mathrm{W}\right)$, sited near the eastern margin of the basin $300 \mathrm{~m}$ to the south of Dead Brook, a slow-moving stream that comprises the largest single inflow into Oromocto Lake (Figure 1). 
This was the deepest sampling station $(6 \mathrm{~m})$ and was located in an area with a muddy bottom and scant vegetation cover $(<5 \%)$. Water property data indicated that all stations were well above any potential thermocline in the lake, meaning that low oxygen conditions would not be a limiting factor in controlling the makeup of the arcellinidan assemblages.

After positioning the quadrat on the lake bed at each sample station, the upper $3 \mathrm{~mm}$ of sediment was carefully collected in situ, from the intersections between the gridlines, using an inert polystyrene laboratory spoon and placed in pre-labeled sample bottles. The full allocation of 16 samples was collected from Q1. Two sample bottles were lost during subsequent sampling at Q2 and Q3 (Q2 sample B3 and Q3 sample B3), resulting in 15 samples being collected from each of these stations, giving a total of 46 samples.

\section{Laboratory Methods}

\section{Estimation of vegetation cover}

A general estimation of the vegetation cover within each quadrat was determined post sampling by examining underwater photographs taken each quadrat prior to sampling. The percentage of vegetation cover was first estimated for each grid in the three quadrats, which was then averaged to estimate the total coverage of vegetation in each quadrat. 


\section{Geochemical Analysis}

To provide insights into geochemical variability at a $<1 \mathrm{~m}^{2}$ sampling scale, and to help explain possible variation in Arcellinida communities, all the 46 samples were, also, analyzed using Itrax high-resolution core-scanning x-ray fluorescence (Itrax-XRF). Following procedures outlined in Gregory et al., [24], $5 \mathrm{cc}$ of sediment was sub-sampled from each quadrat sample and homogenized, centrifuged at $4000 \mathrm{rpm}$ for 4 minutes, and the supernatant decanted. The samples were allowed to dry at room temperature until they reached the consistency of moist paste.

Samples were then transported to the McMaster University Itrax Core Scanning Facility, Hamilton, Ontario, and loaded into a custom-made acrylic container with $0.5 \mathrm{~cm}$ wide partitions for analysis (see [24] for additional description of the Sequence Sample Reservoir [SSR] vessel). Samples were analyzed using the Mo x-ray tube at $30 \mathrm{kV}$ and $17 \mathrm{~mA}$ for 20 seconds at $0.2 \mathrm{~mm}$ resolution using standard Itrax procedures [25]. Itrax-XRF analysis using the SSR provided 15 data values for each sample. The median value for each sample was taken as a measure of central tendency as many elements had a non-normal distribution ([24]; Supplementary Table 1).

\section{Loss-On-Ignition}

Loss on Ignition (LOI) analysis was performed on subsamples from all 46 samples to determine the percentages of moisture, organics, and carbonates (see [26]). The moisture content was determined by comparing measurements before and after samples were placed in an oven at $100^{\circ} \mathrm{C}$ for 24 hours. A Fisher Scientific Muffle Oven was then programmed for sequential 
burning at $550^{\circ} \mathrm{C}$ and $900^{\circ} \mathrm{C}$ to determine percentages of organics and carbonates, respectively (Supplementary Table 1).

\section{Particle Size Analysis}

Subsamples from all 46 samples were prepared for particle size analysis by digestion with $10 \%$

$\mathrm{HCl}$ and $35 \% \mathrm{H}_{2} \mathrm{O}_{2}$ to break down carbonate and organic material, respectively [27]. The reaction was sped up by placing samples in an $80^{\circ} \mathrm{C}$ water bath. The remaining sediment was analyzed using a Beckman Coulter LS 13320 laser diffraction analyzer with a universal liquid medium (ULM) sample chamber. The measurements were compiled using MATLAB and processed with GRADISTAT (Version 8; [28]; Supplementary Table 1).

\section{Micropaleontological Analysis}

Arcellinida analysis was carried out on all 46 sediment-water interface samples. The samples were homogenized and 1-cc subsamples were collected. The subsamples were wet sieved through a $297-\mu \mathrm{m}$ mesh and then a $37-\mu \mathrm{m}$ mesh to remove both coarse and fine organic and mineral detritus respectively. The subsamples were subsequently subdivided into six aliquots for quantitative analysis using a wet splitter [29]. Arcellinida taxa in each aliquot were distributed across a gridded petri dish, identified and quantified using an Olympus SZH dissecting binocular microscope. A statistically significant number of arcellinidan species and strains was enumerated, ranging between 200-300 counts per sample ([see 30]; Supplementary Table 2). Identification of Arcellinida specimens was carried out with reference to well-illustrated papers that used the same species/strain taxonomic approach as presented here, principally $[4,18,31])$. 
The Shannon-Weaver Diversity index (SDI) [32] was used as a measure of diversity within a given sample. Specimens of the most common species and strains were picked from samples using a fine-tipped brush, transferred to a Scanning electron microscope (SEM) stub covered in double sided tape, coated in gold to enhance conductivity, and imaged using a Tescan Vega-II XMU VP scanning electron microscope in the Carleton University Nano Imaging Facility. All SEM plates were formatted using Adobe Photoshop ${ }^{\text {TM }}$ CS 2017.

\section{Statistical Analysis}

\section{Data Screening}

Prior to statistical analysis, both species and environmental datasets were screened according to Reimann et al. [33]. Samples comprising more than 50\% insignificant species counts or environmental variable values were removed. In addition to the exclusion of the samples lost during field work (Q2B3 and Q3B3), this screening step resulted in the removal of four additional samples from the subsequent statistical analyses (Q1A1, Q2D3, Q3D3, and Q3D4; Table 1, Table 2), reducing the total of analyzed samples to 42 . 


\section{Cluster Analysis}

PVClust R statistical software package was used to group samples containing statistically similar arcellinidan assemblage compositions and to determine the statistical significance of the identified assemblages. The analysis was carried out using Ward's Minimum variance method [34] and recorded as Euclidean distances [35].

Non-metric Multidimensional Scaling (NMDS)

Non-metric Multidimensional Scaling (NMDS; [36]) was used to analyze the spatial patterns occurring within the arcellinidan dataset in two-dimensional ordination space, using Euclidean distances.

\section{Redundancy Analysis and Variance Partitioning}

RDA [37] was carried out to assess the relationship between the 28 species and strains of Arcellinida and a select set of 8 out of 31 measured environmental variables within the 42 surface sediment samples that passed the screening procedure. Partial RDA was conducted with the Variance Partitioning test to determine the statistical significance of selected environmental parameters, which is essential for determining the main drivers for variability within the identified Arcellinida assemblages. 


\section{Results}

\section{Cluster Analysis}

A total of 28 Arcellinida species and strains were observed in samples from Oromocto Lake, with number of specimens/cc ranging from 281-775 (mean $=545$; Supplementary Table 2). The results of the cluster analysis show that the arcellinidan samples can be divided into two statistically distinct (96\% [>2 $\delta$ ] significance) assemblages, Assemblage 1 (A1), and Assemblage 2 (A2) (Figure 3). Assemblage A1 corresponded with samples from Q1, while A2 comprises samples from Q2 and Q3. The cluster algorithm produced an additional bifurcation within A2 that shows samples from Q2 and Q3 further clustering into two subgroupings (A2a and $\mathrm{A} 2 \mathrm{~b}$, respectively). However, with a statistical separation of only $61 \%[<1 \delta]$ significance, there is inadequate statistical evidence to recognize the variance between the faunas of Q2 and Q3 as more than informally designated sub-assemblages (Figure 3). The samples from each quadrat grouped distinctively as A1 (Q1), A2a (Q2), and A2b (Q3), with the exception of four outliers: Q1A2, Q1A3, and Q3A4, which grouped with the Q2 samples in A2a; while Q2A4 grouped with Q3 samples in A2b (Figure 3).

\section{Non-metric Multidimensional Scaling}

The NMDS analysis produced results that were similar to those obtained from the cluster analysis. As observed in the cluster analysis results, samples from within each quadrat grouped 
together (Figure 4), however, the results of the NMDS analysis did not provide the same clear distinction between assemblages (Figure 3). Instead, the NMDS results showed some overlap between samples from Q1 (A1) and Q2 (A2a), and considerable overlap between samples from Q2 (A2a) and Q3 (A2b). There was no overlap between samples from Q1 (A1) and Q3 (A2b). This overlap between quadrats provides further evidence of the low level of significance associated with the sub-assemblages $\mathrm{A} 2 \mathrm{a}$ and $\mathrm{A} 2 \mathrm{~b}$ in the cluster analysis results (Figure 3, 4).

\section{Redundancy Analysis and Variance Partitioning}

The RDA and partial RDA with variance partitioning was carried out on the environmental data (Itrax-XRF-derived geochemistry, LOI-derived organic and carbonate content, particle size analysis parameters; Table 1) and species data (quantified Arcellinida species and strains; Table 2). The results indicated that three axes were significant. Axes one and two were significant at $p<0.05$ and axis three was significant axis three was significant at $p<0.45$. This explained $37.1 \%$ of the total variance in the data. Using a manual assessment approach (i.e. known environmental significance and/or adverse impact of the variable), coupled with Variance Partitioning test, it was determined that, of the 31 variables assessed, seven were most important in controlling the variability within the arcellinidan assemblages. Potassium was the most statistically significant controlling variable, explaining $12.6 \%$ of the variance, followed by $\mathrm{S}(6.2 \%)$, Ti (5.4\%), Zn (4.6\%), Fe (4.3\%), Sb (4.3\%), and Mn (4.1\%). Collectively, these seven variables explained $41.5 \%$ of the total variance (Figure $5 \mathrm{~b}$ ). The contribution of other important substrate-related environmental variables (e.g. LOI and PSA parameters) toward explaining the variance in the identified Arcellinida assemblages was insignificant, hence resulting in the exclusion of these 
variables from all ensuing analyses. An additional variable, Shannon Diversity Index (SDI), was plotted passively on the RDA plot. The RDA tri-plot shows each quadrat clearly discriminated from the others and impacted by distinct environmental variables (Figure 5a). Quadrat 1 samples were closely correlated with Mn, and S, while Q3 samples were highly influenced by Fe, Ti, K, $\mathrm{Zn}$, and Sb. The Quadrat 2 grouped alone and was seemingly affected equally by the seven variables (Figure 5a). The special variability grid (Figure 6) demonstrated the same results as the RDA tri-plot. The notable difference in the relative amounts (in counts per seconds) of each of the seven statistically significant elements, as well as the SDI, can be seen across the three quadrats. The increase of Ti, and the decrease in SDI, from Q1 to Q3 were the most visible (Figure 6).

\section{Arcellinida Assemblages}

\section{Assemblage 1 (A1)}

The fauna within A1 is dominated by Difflugia oblonga Ehrenberg 1832 strain "oblonga" ( $\overline{\mathrm{x}}=$ 19.0\%, $\sigma=2.3)$, Difflugia elegans Penard $1890(\overline{\mathrm{x}}=10.6 \%, \sigma=2.6)$, and Centropyxis aculeata (Ehrenberg 1832) strain "aculeata" $(\overline{\mathrm{x}}=8.8 \%, \sigma=2.5)$. Also common in samples of A1 are Difflugia glans Penard 1902 strain "glans" $(\overline{\mathrm{x}}=7.4 \%, \sigma=2.1)$, and Centropyxis constricta (Ehrenberg 1843) strain "aerophila" $(\overline{\mathrm{x}}=6.4 \%, \sigma=1.6)$ (Figure 7,8$)$. The SDI values from the samples within A1 range from 2.53 - 2.96. Samples associated with A1 were collected from the shallowest $(3 \mathrm{~m})$, most vegetated $(\sim 91.7 \%$ cover $)$ of the three quadrat stations, with mostly silty $(\overline{\mathrm{x}}=66 \%, \sigma=12)$ to sandy $(\overline{\mathrm{x}}=25 \%, \sigma=14)$ substrates. 
Assemblage $2 a$ (A2a)

As with assemblage A1, A2a is dominated by $D$. oblonga "oblonga" $(\overline{\mathrm{x}}=23.2 \%, \sigma=2.5), D$. glans "glans" $(\overline{\mathrm{x}}=11.2 \%, \sigma=2.2)$, D. elegans $(\overline{\mathrm{x}}=10.0 \%, \sigma=2.7)$, and C. aculeata "aculeata" $(\overline{\mathrm{x}}=7.1 \%, \sigma=2.2)$. A2a also includes relatively high numbers of Lesquereusia spiralis (Ehrenberg 1840) $(\overline{\mathrm{x}}=6.7 \%, \sigma=1.5)($ Figure 7,8$)$. The SDI values from A2a $(1.69-2.80)$ are slightly lower than those of A1 and have a broader range. Cluster analysis revealed that A2a was mainly composed of samples from Q2 (5 m water depth, with moderate vegetation cover (66\%)), and with the addition of outliers Q1A3 and Q3A4. As observed for A1, the A2a samples were obtained from silty $(\overline{\mathrm{x}}=54 \%, \sigma=13)$ to sandy $(\overline{\mathrm{x}}=37 \%, \sigma=15)$ sediments.

\section{Assemblage $2 b(A 2 b)$}

$\mathrm{A} 2 \mathrm{~b}$ was highly similar to A1 and A2a, with the dominant fauna being D. oblonga "oblonga" ( $\overline{\mathrm{x}}$ $=26.0 \%, \sigma=3.2), D$. glans "glans" $(\overline{\mathrm{x}}=11.8 \%, \sigma=2.2)$, L. spiralis $(\overline{\mathrm{x}}=8.1 \%, \sigma=2.0)$, and $D$. elegans $(\overline{\mathrm{x}}=7.1 \%, \sigma=1.9)$. A2b also includes moderate frequencies of Cucurbitella tricuspis (Carter 1856) $(\overline{\mathrm{x}}=5.3 \%, \sigma=1.4)($ Figure 7,8$)$. The SDI values from the samples in A2b (1.732.52) were significantly lower than those of A1 but still within the range of the A2a values. Although the cluster analysis indicated that A2b mostly contains samples from the deep (6 m), non-vegetated Q3 station (with the addition of sample Q2A4), the substrate composition of 
samples within A2b is very similar to that of A1 and A2a, with $61 \% \pm 10 \sigma$ silt and $29 \% \pm 13 \sigma$ sand.

\section{Discussion}

\section{Drivers of Arcellinidan Assemblage Variability}

The cluster and NMDS analyses show that, although the faunal assemblages within the three quadrats were relatively similar, there were identifiable differences when directly comparing the assemblages within Q1 (shallow, heavily vegetated substrate) and Q3, sited in deeper water 300 m southward of the mouth of Dead Brook on a non-vegetated muddy-silt substrate. Despite these differences, there was considerable overlap between the assemblages found in Q1 and Q2 and between the assemblages found in Q2 and Q3. The most abundant species identified did not vary significantly between any of the three quadrats though, which included; D. oblonga "oblonga", D. glans "glans", D. elegans, C. aculeata "aculeata", L. spiralis, C. constricta "aerophila", and C. tricuspis. This mixed assemblage of both centropyxids and difflugids with moderate to high diversity (SDI >1.7) is typical of oligotrophic lake systems [7, 38, 39]. Although nonagglutinated Arcellinida are occasionally observed in oligotrophic systems, none were observed in the sampled Oromocto Lake sediments. The relative abundance of the observed taxa provides important data on the relative health and productive environmental conditions of the basin [39]. The general overall faunal similarity is, in part, attributable to the relatively similar muddy-silt substrate as determined by grain size analysis, and similar organic content (Table 1), which are 
both important controls on the distribution of arcellinidan taxa [19]. Another contributing factor to the relatively similar sedimentary regime in the basin is related to the relatively shallow waters of the north basin that permit more wave and wind driven mixing within the water column, which prevents nutrient gradients from forming [38].

Various diversity indices are commonly used as a quantitative measure of not only how many species are present in a sample, but how evenly individual specimens are distributed as well [40]. Species diversity is thus an important component of all lake ecosystems, with the SDI being one of the most commonly used in arcellinidan research [19]. SDI is typically only passively plotted in statistical analysis (e.g. RDA) as this value is an amalgamation of directly measured variables that contribute to the species makeup in a given assemblage [4]. In typical arcellinidan assemblages a SDI value of 1.5-2.5 is indicative of a transitional state, while values below 1.5 are characteristic of an environment under stress $[19,41]$. In the Oromocto Lake samples, SDI varied from relatively high values associated with A1 (2.53-2.96), which is contributed to by the diverse niche space available within the highly-vegetated Q1, to lower transitional SDI (1.73-2.52) values found in A2b, the assemblage dominated by samples from in Q3. These depressed SDI values are to be expected in the reduced niche space available on the non-vegetated silty-mud substrate, with probable additional contributions from unknown confounding variables related to the site being adjacent to the mouth of Dead Brook. Prentice et al. [42] investigated the influence of aquatic vegetation composition on arcellinidan assemblages in a dated sediment record from Loch Leven, Scotland. Highly diverse arcellinidan assemblages, mainly dominated by difflugid taxa (e.g. D. oblonga "oblonga") were primarily associated with plants that are indicative of oligo-mesotrophic conditions, particularly isoetids, which may play an important role in maintaining oxygen levels in healthy benthic communities. In contrast, they 
noted that higher proportions of species such as C. tricuspis, Mediolus corona and Difflugia amphora were more typically associated with inferred eutrophic conditions. This may in part reflect reduced oxygen conditions associated with the decomposition of charophyte biomass or changes in plant community structure [42]. While the structure of the aquatic macrophyte community characterizing the northern basin of Oromocto Lake was not investigated in this study, the dominance of D. oblonga "oblonga" throughout all assemblages, coupled with the overall intermediate to high SDI values, reflects the relatively stable oligotrophic conditions observed.

\section{Variables Contributing to Assemblage Composition}

The RDA results identified seven significant environmental parameters that can be used to provide evidence as to why the assemblages in Q1 and Q3 plotted distinctly (Figure 5, 6). Titanium, Fe and $\mathrm{K}$ are all proxies of runoff, as they are geochemically stable, hosted by resistant minerals, and generally unaltered in most geochemical environments [43, 44]. Titanium in particular is a proxy for erosion and transport of fine sand [45]. It has previously been demonstrated that arcellinidan taxa are sensitive to runoff, which influences a wide variety of ecologically important variables (e.g. grain size, nutrients). Peak occurrences of all three elements were in Q3, downstream of the mouth of Dead Brook, and they were least abundant in Q1, the most distal sample station.

The proportions of $\mathrm{Zn}$ and $\mathrm{Sb}$ are also highest in Q3. Zinc enrichment is generally associated with anthropogenic sources, or very high terrigenous supply [46, 47]. Antimony is found naturally at low concentrations, but higher levels are usually associated with 
anthropogenic input [48]. As Dead Brook has its origin in an area of cleared farmland and built infrastructure, and is also a source of terrigenous sediment during spring runoff, this is the most likely explanation for elevated levels of $\mathrm{Zn}$ and $\mathrm{Sb}$ in Q3.

Manganese and S concentrations are both highest in Q1. Manganese is naturally common within the earth's crust and is easily soluble in groundwater [49]. Oromocto Lake is characterized by an anticline that dips toward the western side of the northern basin, where Q1 is located, and Mn nodules are common in the Carboniferous bedrock found there [50]. Dissolved Mn originating from these nodules is transported as groundwater downslope within the anticline and outflows in the numerous springs found along the western shore, where it subsequently preferentially accumulates in the basin near the source. Sulfur is found in relatively low concentrations in the environment, but higher levels occur in nutrient-rich locations where natural biochemical S cycling occurs [51]. This is likely why there is a spike in S concentration within the highly vegetated, nutrient-rich site at Q1, while the poorly vegetated Q3 is characterized by lower levels of S. Interestingly, other substrate-related environmental variables (e.g. LOI and PSA parameters) explained an insignificant portion of the total variance and thus were excluded from all statistical analysis. This is not surprising, however, as the values of these variables were relatively uniformed across all quadrats and exhibited low variance throughout the entire environmental dataset.

\section{Homogeneity of Closely Spaced Samples: Are Replicate Samples Necessary?}

In addition to collecting samples from sites across the northern basin of Oromocto Lake, the experimental design for this study included the collection of multiple samples at $10 \mathrm{~cm}$ 
spacing within quadrats at each sample station, to determine whether arcellinidan faunas from similar adjacent sedimentary environments are homogenous or characterized by a patchy assemblage distribution. This type of investigation has not previously been carried out using arcellinidans, although similar research has been carried out on marine benthic foraminifera (an allied microfossil group). Buzas et al., (2015 [22]) concluded that the density of benthic foraminifera varies spatially and temporally within a habitat, but that these differences are not always statistically significant. In this study, the cluster analysis, NMDS analysis, and RDA results indicate that the distribution of arcellinidan species and strains is quite homogenous in closely spaced samples. The samples within each of the three quadrats grouped closely together, with minimal outliers (Figure 3, 4, 5). These results indicate that when collecting a sedimentwater interface sample from open water sampling stations, there will be a high level of confidence that the arcellinidan assemblage observed will be reflective of the sample's environment, meaning that the collection of replicate samples for a given habitat is not required. The concentration of the arcellinidan populations quantified were also very similar within each quadrat (Table 2), indicating that this important ecological factor does not vary at the local scale when key environmental controls (substrate, water depth, vegetation cover) are similar. Multiple station sampling, however, will likely be necessary when different habitats within a basin are assessed (e.g. water depth in littoral zone vs. open water sites), or when a lake is impacted by environmental stressors (e.g. eutrophication, industrial or municipal contamination) that might have a different impact across a lake basin. 


\section{Conclusions}

The objectives of this study were to assess (1) the variability of arcellinidan assemblages from relatively similar open water habitats within a single lake basin; and (2) determine the homogeneity of faunas from closely spaced samples (sample reproducibility). Forty-two samples from three stations across the northern basin of Oromocto Lake, NB were used to obtain arcellinidan species distributional data that was compared against various measured environmental parameters and SDI. Cluster analysis, NMDS analysis, and the RDA results were used to characterize the distinct environmental characteristics that influenced the arcellinidan assemblages found within each quadrat. The results indicate that closely spaced $(\sim 10 \mathrm{~cm})$ samples yield highly homogenous arcellinidan assemblages, indicating that local faunal patchiness is not an issue with this group, and that analysis of replicate samples is not a requirement in open water settings. However, multiple stations may need to be assessed across lake basins to capture full environmental variability. For instance, samples collected from midbasin in a deep lake with a thermocline, where low oxygen conditions prevail, would not provide a representative arcellinidan population. As arcellinidans are oxygen consuming heterotrophic protists, samples from sites shallower than the thermocline are required under these conditions [7, 19]. In addition, as demonstrated by the assemblage characteristics of the site at Q3, inflow streams, such as Dead Brook, are likely to affect the homogeneity of a lake bottom and should be avoided, or included as a supplemental station if the physical characteristics of these environments are of interest to the researcher. 


\section{References}

1. Asioli A, Medioli FS, Patterson RT (1996) Thecamoebians as a tool for reconstruction of paleoenvironments in some Italian lakes in the foothills of the southern Alps (Orta, Varese and Candia). J Foramin Res 26:248-263

2. Dalby AP, Kumar A, Moore JM, Patterson RT (2000) Utility of arcellaceans (thecamoebians) as paleolimnological indicators in tropical settings: Lake Sentani, Irian Jaya, Indonesia. J Foraminifer Res 30:135-142

3. Farooqui A, Kumar A, Swindles GT (2011) Thecamoebian communities as proxies of seasonality in Lake Sadatal in the Ganga-Yamuna Plains of North India. Palaeontologia Electronica 15:3A, $19 \mathrm{pp}$

4. Nasser NA, Patterson RT, Roe HM, Galloway JM, Falck H, Palmer MJ, Spence C, Sanei H, Macumber AL, Neville LA (2016) Lacustrine arcellina (testate amoebae) as bioindicators of arsenic contamination. Microb Ecol 72:130-149

5. Neville LA, McCarthy FMG, MacKinnon MD (2010) Seasonal environmental and chemical impact on thecamoebian community composition in an Oil Sands reclamation wetland in Northern Alberta. Palaeontol Electron 13.2.13A, 14 pp

6. Patterson RT, Barker T, Burbidge SM (1996) Arcellaceans (thecamoebians) as proxies of arsenic and mercury contamination in northeastern Ontario lakes. J Foramin Res 26:172183

7. Patterson RT, Lamoureux EDR, Neville LA, Macumber AL (2013) Arcellacea (Testate Lobose Amoebae) as $\mathrm{pH}$ Indicators in a pyrite mine-acidified lake, Northeastern Ontario, Canada. Microb Ecol 65:541-554 
8. Patterson RT, Kumar A (2000a) Assessment of arcellacean (thecamoebian) assemblages, species, and strains as contaminant indicators in James Lake, Northeastern Ontario, Canada, J Foramin Res 30:310-320

9. Patterson RT, Kumar A (2000b) Use of arcellacea to gauge levels of pollution and remediation of industrially polluted lakes. In: Martin RE (ed) Environmental Micropaleontology, v. 15 of Topics in Geobiology, Kluwer Academic/Plenum Publication, p. $257-278$

10. Reinhardt EG, Dalby AP, Kumar A, Patterson RT (1998) Arcellaceans as pollution indicators in mine tailing contaminated lake near Cobalt, Ontario, Canada. Micropaleontol 44:131-148

11. Roe HM, Patterson RT (2006) Distribution of thecamoebians (testate amoebae) in small lakes and ponds, Barbados, West Indies. J Foramin Res 36:116-134

12. Roe H, Patterson RT, Swindles GT (2010) Controls on the contemporary distribution of lake thecamoebians (testate amoebae) within the Greater Toronto Area and their potential as water quality indicators. J Paleolimnol 43:955-975

13. Medioli FS, Scott DB (1983) Holocene arcellecea (Thecamoebians) from eastern Canada. Cushman Foundation For Foraminiferal Research special Publication 21:63

14. Medioli, F.S., Scott, D.B., Collins, E.S., McCarthy, F.M.G., 1990a. Fossil thecamoebians: present status and prospects for the future. In: Hemleben, C., Kaminski, M.A., Kuhnt, W., Scott, D.B. (Eds.), Paleoecology, Biostratigraphy, Paleoceanography and Taxonomy of Agglutinated Foraminifera. NATOAdvanced Study Institute Series, Series C, Mathematical and Physical Sciences 327, pp 813-840 
15. Medioli, F.S., Scott, D.B., Collins, E.S., Wall, J.H., 1990b. Thecamoebians from the early Cretaceous deposits of Ruby Creek, Alberta (Canada). In: Hemleben, C., Kaminski, M.A., Kuhnt, W., Scott, D.B. (Eds.), Paleoecology, Biostratigraphy, Paleoceanography and Taxonomy of Agglutinated Foraminifera. NATOAdvance d Study Institute Series, Series C, Mathematical and Physical Sciences 327, pp 793-812

16. Porter SA, Knoll AH (2000) Testate amoeba in the Neoproterozoic Era: evidence from vase-shaped microfossils in the chuar group, Grand Canyon. Paleobiology 26:360-385

17. Gehrels WR, Roe HM, Charman DJ (2001) Foraminifera, testate amoebae, and diatoms as sea-level indicators in UK saltmarshes: a quantitative multiproxy approach. J Quat Sci $16: 210-220$

18. Roe HM, Patterson RT (2014) Arcellacea (testate amoebae) as bio-indicators of road salt contamination in lakes. Microb Ecol 68:299-313

19. Patterson RT, Kumar A (2002) A review of current testate rhizopod (thecamoebian) research in Canada. Palaeogeogr Palaeoclimatol Palaeoecol 180:225-251Wall AAJ, Gilbert D, Magny M, Mitchell EAD (2010) Testate amoeba analysis of lake sediments: impact of filter size and total count on estimates of density, species richness and assemblage structure. J Paleolimnol 43:689-704

20. Patterson RT, Roe HM, Swindles GT (2012) Development of an Arcellacea (testate lobose amoebae) based transfer function for sedimentary phosphorus in lakes. Palaeogeogr Palaeoclimatol Palaeoecol 348-349:32-44

21. Galloway JM, Sanei H, Patterson RT, Mosstajiri, Hadlari T, Falck H (2012) Total arsenic concentrations of lake sediments near the City of Yellowknife, Northwest Territories. Geological Survey of Canada Open File 7037, 47 pp 
22. Buzas MA, Hayek LC, Jett JA, Reed SA (2015) Pulsating Patches: History and Analysis of Spatial, Seasonal, and Yearly Distribution of Living Benthic Foraminifera. Smithsonian Institution Scholarly Press, pp 91

23. Pronk AG, and Allard S. (2003). Landscape map of New Brunswick. New Brunswick Division, Map NR-9 (scale $1: 440$ 000).

24. Gregory BR, Reinhardt EG, Macumber AL, Nasser NA, Patterson RT, Kovacs SE, Galloway JM (2017) Sequential sample reservoirs for Itrax-XRF analysis of discrete samples. Journal of Paleolimnology 57:287-293

25. Croudace IW, Rindby A, Rothwell RG (2006) ITRAX: description and evaluation of a new multi-function X-ray core scanner. In: Geological Society of London, Special Publication, pp 267

26. Heiri O, Lotter AF, Lemcke G (2001) Loss on ignition as a method for estimating organic and carbonate content in sediments: reproducibility and comparability of results. Journal of Paleolimnology 25:101-110

27. Murray A (2002) Is laser particle size determination possible for carbonate-rich lake sediments? J Paleolimnol 27:173-183

28. Blott SJ, Pye K (2001) GRADISTAT: a grain size distribution and statistics package for the analysis of unconsolidated sediments. Earth Surf Process Landf 26:1237-1248

29. Scott DB, Hermelin JOR (1993) A device for precision splitting of micropaleontological samples in liquid suspension. J Paleontol 67:151-154

30. Patterson RT, Fishbein A (1989) Re-examination of the statistical methods used to determine the number of point counts needed for micropaleontological quantitative research. J Paleontol 63:245-248 
31. Cullen J (2016) Lacustrine Intra-Basinal Arcellinidan (Testate Lobose Amoeba) Assemblage Dynamics: Implications for Paleontological Reconstruction (Honours Thesis, Carleton University, Ottawa)

32. Shannon C E (1948) A mathematical theory of communication. The Bell System Technical Journal, 27: 379-423 and 623-656.

33. Reimann C, Filzmoser P, Garrett RG, Dutter R (2008) Statistical Data Analysis Explained: Applied Environmental Statistics with R. John Wiley \& Sons, Ltd. ISBN:978$0-470-98581-6$

34. Ward JH (1963) Hierarchical grouping to optimize an objective function. J Am Stat Assoc 58:236-244

35. Fishbein E, Patterson RT (1993) Error-weighted maximum likelihood (EWML): a new statistically based method to cluster quantitative micropaleontological data. J Paleontol 67: $475-485$

36. Ramette A (2007) Multivariate analyses in microbial ecology. FEMS Microbiol Ecol $62: 142-160$

37. van den Wollenberg AL (1977) Redundancy analysis. An alternative for canonical correlation analysis. Psychometrika 42:207-219

38. Patterson RT, MacKinnon KD, Scott DB, Medioli FS (1985) Arcellaceans ("Thecamoebians") in small lakes of New Brunswick and Nova Scotia: modern distribution and Holocene stratigraphic changes: J Foramin Res 15:114-137

39. Imboden DM, Lemmin U, Joller T, Schurter M (1983) Mixing processes in lakes: Mechanisms and ecological relevance. Schweizerische Zeitschrift für Hydrologie 45:1144 
40. Hill MO (1973) Diversity and evenness: a unifying notation and its consequences. Ecology 54: 427-432.

41. Magurran AE (1988) Ecological diversity and its measurement. Princeton University Press, Princeton, pp 185

42. Prentice SV, Roe HM, Bennion H, Sayer CD, Salgado J (2017) Refining the palaeoecology of lacustrine testate amoebae: insights from a plant macrofossil record from a eutrophic Scottish Lake. Journal of Paleolimnology: 1-19

43. Boës X, Rydberg J, Martinez-Cortizas A, Bindler R, Renberg I. (2011) Evaluation of conservative lithogenic elements ( $\mathrm{Ti}, \mathrm{Zr}, \mathrm{Al}$, and $\mathrm{Rb})$ to study anthropogenic element enrichments in lake sediments. J Paleolimnol 46:75-87

44. LoDico JM, Flower BP, Quinn TM (2006) Subcentennial-scale climatic and hydrologic variability in the Gulf of Mexico during the early Holocene. Paleoceanography 21, Article PA3015

45. Davies SJ, Lamb HF, Roberts SJ (2015) Micro-XRF core scanning in palaeolimnology: recent developments. In Rothwell RG, Croudace IW (eds.) Micro-XRF studies of sediment cores: Applications of a non-destructive tool for the environmental sciences. Dordrecht, Springer, p 189-226 (Developments in Paleoenvironmental Research, 17)

46. Hebbeln D, Scheurle C, Lamy F (2003) Depositional history of the Helgoland mud area, German Bight, North Sea. Geo-Marine Letters 23: 81-90

47. Rothwell RG, Croudace IW (2015) Twenty years of XRF core scanning marine sediments: what do geochemical proxies tell us? In Rothwell RG, Croudace IW (eds) Micro-XRF studies of sediment cores: Application of a non-destructive tool for the environmental sciences. Dordrecht, Springer, p. 25-102 
48. Picard C, Bosco M (2003) Soil antimony pollution and plant growth stage affect the biodiversity of auxin-producing bacteria isolated from the rhizosphere of Achillea ageratum L. FEMS Microbiol Ecol 46:73-80

49. Delfino JJ, Bortleson GC, Lee GF (1968) Distribution of Mn, Fe, P, Mg, K, Na, and Ca in the Surface Sediments of Lake Mendota, Wisconsin. Environmental Science and Technology 3:1189-1192 Robb, 1870

50. Report of Mr. Charles Robb, addressed to Sir William Logan, F.R.S., F.G.S., Director of the Geological Survey in Report of Progress From 1866 to 1869 Accompanied by Geological and Topographical Maps, p. 173-209. Dawson Bros. Montreal

51. Holmer M, Storkholm P (2001) Sulphate reduction and sulphur cycling in lake sediments: a review. Freshwater Biology 46:431-451

52. Carter HJ (1856) Notes on the freshwater Infusoria of the island of Bombay, Ann Mag Nat Hist 18, 104:115-132

53. Carter HJ (1864) On freshwater Rhizopoda of England and India. Ann Mag Nat Hist, ser $3,13: 18-39$

54. Deflandre G (1929) Le genre Centropyxis Stein. Arch Protistenkd 67:323-375

55. Ehrenberg CG (1830) Organisation, systematik und geographisches Verhältnis der Infusionsthierchen. Königl Akad Wiss, Berlin

56. Ehrenberg CG (1832) Über die Entwicklung und Lebensdauer der Infusionsthiere, nebst ferneren Beiträgen zu einer Vergleichung ihrer organischen Systeme. Abh Akad Wiss Berlin 1831:1-154

57. Ehrenberg CG (1840) Das grössere Infusorienwerke. Abh Akad Wiss Berlin 198-219 
58. Ehrenberg CG (1843) Verbreitung und Einfluss des mikroskopischen Lebens in Süd-und Nord Amerika. Königl Preufs Akad Wiss Berlin 1841, pp 181

59. Hempel A (1898) A list of the Protozoa and Rotifera found in the Illinois River and adjacent lakes at Havana, Ill. Illinois State Laboratory of Natural History Bulletin, 5:301388

60. Leidy J (1874) Notice of some fresh-water and terrestrial rhizopods, P Acad Nat Sci Phila $26: 86-88$

61. Penard E (1890) Catalog der nackten und schalentragenden Rhizopoden von Wiesbaden. Jarbuch der nassavischen Vereins für Naturkunde 43:67-72

62. Penard E (1902) Faune Rhizopodique du Bassin du Lèman. Henry Kündig, Libraire de L’institut, Genéve, pp 712

63. Wallich GC (1864) On the process of mineral deposit in the rhizopods and sponges, as affording a distinctive character, Ann Mag Nat Hist Ser 3, 13:72-82 


\section{Figures in Text}

Fig. 1 Map of the study region, Oromocto Lake, New Brunswick, showing the locations of the three sampled quadrats.

Fig. 2 Photos of underwater operations during sample collection showing quadrat design. (A) sampling using SCUBA gear; (B) relatively vegetated conditions within Quadrat 1; (C) more sparsely distributed submerged vegetation in Quadrat 2; and (D) the muddy, non-vegetated substrate at Quadrat 3. Sixteen samples from each quadrat (4 rows and 4 columns) were collected, with one sample lost from each of Quadrat 2 and 3 (46 samples total).

Fig. 3 PVClust Cluster Analysis dendrogram for the 42 sediment-water interface samples that had no missing values, with the two major assemblages (A1 and A2) and two sub-assemblages (A2a and A2b) indicated. Below the cluster analysis is a visualization of the assemblage composition within each quadrat. The green squares represent Assemblage 1, the red squares Assemblage 2A, and the blue squares Assemblage 2B. It is apparent that the quadrats show quite uniform assemblage compositions. 
Fig. 4 Non-metric Multidimensional Scaling (NMDS) bi-plot of the 42 samples with the previously defined clusters identified. CAA = Centropyxis aculeata '“aculeata', CAD = Centropyxis aculeata "discoides", CCA = Centropyxis constricta ' aerophila', $\mathrm{CCC}=$ Centropyxis constricta "constricta", $\mathrm{CCS}=$ Centropyxis constricta "spinosa", $\mathrm{CT}=$ Cucurbitella tricuspis, $\mathrm{CK}=$ Cyclopyxis kahli, DA = Difflugia amphora, $\mathrm{DB}=$ Difflugia bidens, $\mathrm{MC}=$ Mediolus corona, $\mathrm{DF}=$ Difflugia fragosa, $\mathrm{DGG}=$ Difflugia glans "glans", DGM = Difflugia glans "magna", DGD = Difflugia glans "distenda", DG = Difflugia globulosa, $\mathrm{DOB}=$ Difflugia oblonga "bryophila", DOL = Difflugia oblonga "lanceolata", DOL = Difflugia oblonga "linearis", DOO = Difflugia oblonga "oblonga", DOS = Difflugia oblonga "spinosa", DOT = Difflugia oblonga "tenuis", DPA = Difflugia protaeiformis "acuminata", DUU = Difflugia urceolata "urceolata", DU = Difflugia urens, DE = Difflugia elegans, LV = Lagenodifflugia vas, $\mathrm{LS}=$ Lesquereusia spiralis, $\mathrm{PC}=$ Pontigulasia compressa.

Fig. 5 (A) Redundancy Analysis (RDA) species-environment sample triplot for the 42 samples. $\mathrm{Ti}=$ Titanium, $\mathrm{Fe}=$ Iron, $\mathrm{K}=$ Potassium, $\mathrm{Zn}=$ Zinc, $\mathrm{Mn}=$ Magnesium, $\mathrm{S}=$ Sulphur, $\mathrm{Sb}=$ Antimony, SDI = Shannon Diversity Index. CAA = Centropyxis aculeata "'aculeata', CAD = Centropyxis aculeata "discoides", $\mathrm{CCA}=$ Centropyxis constricta ' aerophila', $\mathrm{CCC}=$ Centropyxis constricta "constricta", $\mathrm{CCS}=$ Centropyxis constricta "spinosa", $\mathrm{CT}=$ Cucurbitella tricuspis, $\mathrm{CK}=$ Cyclopyxis kahli, DA = Difflugia amphora, $\mathrm{DB}=$ Difflugia bidens, $\mathrm{MC}=$ Mediolus corona, $\mathrm{DF}=$ Difflugia fragosa, DGG = Difflugia glans "glans", DGM = Difflugia glans "magna", DGD = Difflugia glans "distenda", DG = Difflugia globulosa, $\mathrm{DOB}=$ Difflugia oblonga "bryophila", DOL = Difflugia oblonga "lanceolata", DOL = Difflugia oblonga "linearis", DOO = Difflugia oblonga "oblonga", DOS = Difflugia oblonga "spinosa", DOT = 
Difflugia oblonga "tenuis", DPA = Difflugia protaeiformis "acuminata", DUU = Difflugia urceolata "urceolata", DU = Difflugia urens, DE = Difflugia elegans, LV = Lagenodifflugia vas, $\mathrm{LS}=$ Lesquereusia spiralis, $\mathrm{PC}=$ Pontigulasia compressa. (B) Partial Redundancy Analysis (pRDA) and variance partitioning results showing the percentage of Arcellinida distribution variation that is explained by the eight environmental variables.

Fig. 6 Spatial variability grid of the measured eight statistically significant environmental variables across each of the three sample quadrats.

Fig. 7 Scanning electron microscope images of selected Arcellinida tests (shells) from Oromocto Lake. (1-5) Centropyxis aculeata (Ehrenberg 1832) “aculeata”. (6-8) Centropyxis constricta (Ehrenberg 1843) “'aerophila'. (9-13) Centropyxis constricta (Ehrenberg 1843) “constricta”. (14-17) Cucurbitella tricuspis (Carter 1856). (18, 19) Mediolus corona (Wallich 1864). (20) Cyclopyxis kahli (Deflandre, 1929). (21, 22) Difflugia bidens Penard 1902. (23-25) Lagenodifflugia vas (Leidy 1874). (26-28) Lesquereusia spiralis (Ehrenberg 1840). (29, 30) Pontigulasia compressa (Carter 1864).

Fig. 8 (1-3) Difflugia glans (Penard 1902) “magna”. (4-6) Difflugia glans (Penard 1902) "glans”. (7) Difflugia glans (Penard 1902) “distenda”. (8) Difflugia globulosa (Penard 1902). (9) Difflugia fragosa Hempel 1898. (10, 11) Difflugia oblonga Ehrenberg 1832 "lanceolata". (12-14) Difflugia elegans Penard 1890. (15, 16) Difflugia urens Patterson et al. 1985. (17-19) Difflugia oblonga Ehrenberg 1832 “oblonga”. (20, 21) Difflugia oblonga Ehrenberg 1832 “spinosa”. (22, 23) Difflugia oblonga Ehrenberg 1832 “tenuis”. (24, 25) Difflugia protaeiformis Lamark 1816 "acuminata". 